\begin{tabular}{|c|c|}
\hline Title & General Synthesis of Trialkyl- and Dialkylarylsilylboranes: V ersatile Silicon Nucleophiles in Organic Synthesis \\
\hline Author(s) & Shishido, Ryosuke; U esugi, Minami; T akahashi, Rikuro; Mita, T suyoshi; Ishiyama, T atsuo; Kubota, Koji; Ito, Hajime \\
\hline Citation & $\begin{array}{l}\text { Journal of the A merican Chemical Society, 142(33), 14125-14133 } \\
\text { https://doi.org/10.1021/Jacs.0c03011 }\end{array}$ \\
\hline Issue Date & $2020-08-19$ \\
\hline Doc URL & http:/hdl.handle.net/2115/82464 \\
\hline Rights & $\begin{array}{l}\text { This document is the A ccepted Manuscript version of a Published Work that appeared in final form in Journal of the } \\
\text { A merican Chemical Society, copyright c A merican Chemical Society after peer review and technical editing by the } \\
\text { publisher. To access the final edited and published work see https:/pubs.acs.org/doi/10.1021/Jacs.0c03011. }\end{array}$ \\
\hline Type & article (author version) \\
\hline File Information & manuscript (Kubota).pdf \\
\hline
\end{tabular}

Instructions for use 


\title{
General Synthesis of Trialkyl- and Dialkylarylsilylboranes: Versatile Sili- con Nucleophiles in Organic Synthesis
}

\author{
Ryosuke Shishido, ${ }^{\dagger}$ Minami Uesugi, ${ }^{\dagger}$ Rikuro Takahashi, Tsuyoshi Mita, ${ }^{\ddagger}$ Tatsuo Ishiyama ${ }^{\dagger}$ Koji Ku- \\ bota $^{*, \dagger, \sharp}$ and Hajime Ito ${ }^{*}, \dagger, \sharp$ \\ †Division of Applied Chemistry, Graduate School of Engineering, Hokkaido University, Sapporo, Hokkaido 060-8628, Japan \\ Institute for Chemical Reaction Design and Discovery (WPI-ICReDD), Hokkaido University, Sapporo, Hokkaido 001-0021, \\ Japan
}

\begin{abstract}
Compared to carbon-based nucleophiles, the number of silicon-based nucleophiles that is currently available remains limited, which significantly hampers the structural diversity of synthetically accessible silicon-based molecules. Given the high synthetic utility and ease of handling of carbon-based boron nucleophiles, silicon-based boron nucleophiles, i.e., silylboranes, have received considerable interest in recent years as nucleophilic silylation reagents that are activated by transition-metal catalysts or bases. However, the range of practically accessible silylboranes remains limited. In particular, the preparation of sterically hindered and functionalized silylboranes remains a significant challenge. Here, we report the use of rhodium and platinum catalysts for the direct borylation of hydrosilanes with bis(pinacolato)diboron, which allows the synthesis of new trialkylsilylboranes that bear bulky alkyl groups and functional groups as well as new dialkylarylsilylboranes that are difficult to synthesize via conventional methods using alkali metals. We further demonstrate that these compounds can be used as silicon nucleophiles in organic transformations, which significantly expands the scope of synthetically accessible organosilicon compounds compared to previously reported methods. Thus, the present study can be expected to inspire the development of efficient methods for novel silicon-containing bioactive molecules and organic materials with desirable properties. We also report the first ${ }^{11} \mathrm{~B}\left\{{ }^{1} \mathrm{H}\right\}$ and ${ }^{29} \mathrm{Si}\left\{{ }^{1} \mathrm{H}\right\}$ NMR spectroscopic evidence for the formation of $i-\mathrm{Pr}_{3} \mathrm{SiLi}$ generated by the reaction of $i-\mathrm{Pr}_{3} \mathrm{Si}-\mathrm{B}(\mathrm{pin})$ with $\mathrm{MeLi}$.
\end{abstract}

\section{INTRODUCTION}

Historically, organic synthesis has focused mainly on the construction of carbon-based organic molecules. Although both carbon and silicon are group-14 elements, exhibit a valency of 4 , and form tetrahedral compounds, reported methods for synthesizing silicon-based compounds have remained relatively limited. ${ }^{1}$ One of the reasons for this limitation could be the difficulties associated with obtaining synthetically useful silicon nucleophiles. ${ }^{1}$ Various types of carbon nucleophiles have been developed and applied in organic synthesis. Among these, carbon-based boron nucleophiles have become indispensable synthetic reagents for the construction of carbon-carbon-bondforming transformations, such as Suzuki-Miyaura cross-coupling reactions (Scheme 1). ${ }^{2}$ In contrast, the number of siliconbased nucleophiles currently available remains unfortunately limited, which significantly hampers the structural diversity of the synthetically accessible silicon-based molecular frameworks. ${ }^{1}$ Given the high synthetic utility and ease of handling of carbon-based boron nucleophiles, ${ }^{2,3}$ we envisioned that the development of general methods for the preparation of siliconbased boron nucleophiles, i.e., silylboranes, could expand the scope of synthetically accessible silicon-based compounds, thus unlocking novel areas of chemical space for the discovery of silicon-containing pharmaceuticals and light-emitting materials (Scheme 1). ${ }^{4,5}$

In 1960, Seyferth and Ryschkewitsch reported the first compounds that contain a silicon-boron ( $\mathrm{Si}-\mathrm{B})$ bond. ${ }^{6}$ Early research focused mainly on the investigation of the physical properties of these compounds, while more recently, they have been applied in organic synthesis. ${ }^{1}$ Since the pioneering study of Suginome and Ito in 2000, silylboranes have been widely employed as useful reagents for the transition-metal- or base-catalyzed nucleophilic introduction of silyl groups into organic molecules. ${ }^{7-9}$ Whereas the benefits of these developed reactions are well-established, the value of nucleophilic silylation processes would most likely become even more apparent when various types of silicon-based boron nucleophiles are easily available.

Scheme 1. Carbon- and Silicon-based Boron Nucleophiles in Organic Synthesis.

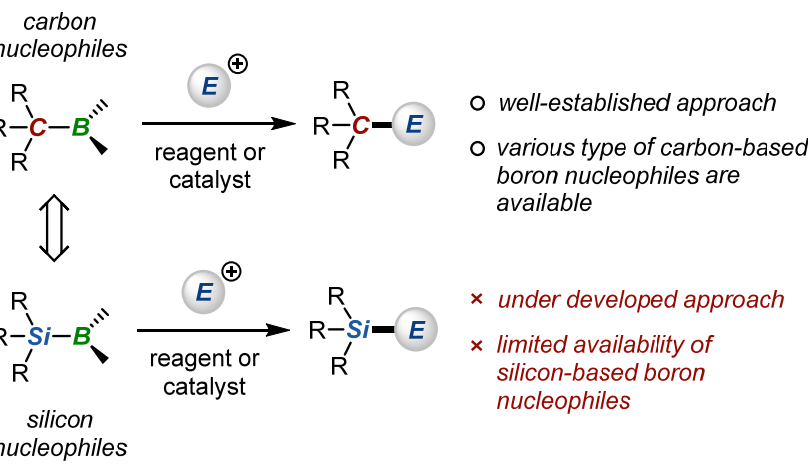

The conventional method for accessing Si-B fragments developed by Suginome and Ito involves a stoichiometric reaction between a silyl anion and a boron electrophile to form the corresponding silylboranes (e.g., 1a-c in Scheme 2a). ${ }^{7}$ Although a variety of protocols to synthesize silyl anions has been reported, the most widely used method is the reaction of a chlorosilane 
with an alkali metal $(\mathrm{K}, \mathrm{Na}$, or $\mathrm{Li})$. However, this method is limited to the preparation of aromatic-group-functionalized silyl anions, $\mathrm{Ar}_{3-\mathrm{n}} \mathrm{R}_{\mathrm{n}} \mathrm{Si}-\mathrm{M}(\mathrm{n}=0-2 ; \mathrm{M}=\mathrm{K}, \mathrm{Na}$, or Li). Given the low reduction potentials of trialkyl chlorosilanes and disilane intermediates for the anion precursor, trialkylsilyl anions are much more difficult to prepare than aryl-substituted silyl anions, which limits access to trialkylsilylboranes such as $\mathbf{1 d}$ via this route (Scheme 2a). ${ }^{10-12}$ In addition, the synthesis of functionalized silyl anions suffers from low functional-group compatibility due to the harsh reduction conditions when using alkali metals. Therefore, only a limited range of silylboranes can be prepared by this approach.

\section{Scheme 2. Synthetic Routes to Silylboranes.}

a. Reaction of boron electrophiles with silyl metals (Suginome and Ito)

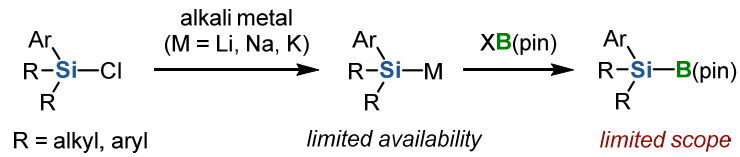

Representative examples of silylboranes

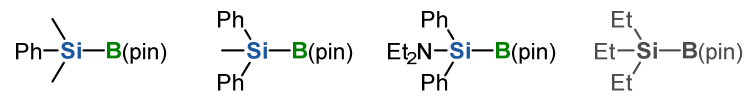

$$
\begin{aligned}
& 1 a \\
& \text { 1b } \\
& 1 c
\end{aligned}
$$

b. Iridium-catalyzed borylation of hydrosilanes (Hartwig)

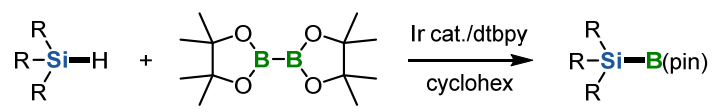

$$
\begin{aligned}
& \mathrm{R}=\mathrm{Et}, n-\mathrm{Pr}, n-\mathrm{Bu} \text { etc. }
\end{aligned}
$$

Representative examples of silylboranes

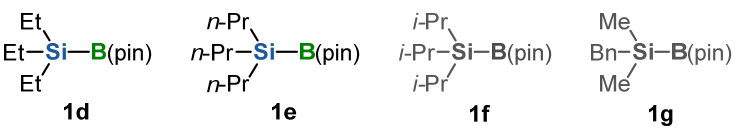

$$
\begin{aligned}
& \text { o simple trialkylsilylboranes } \quad \times \text { bulky } \quad \times \text { aromatic }
\end{aligned}
$$

c. Simple, general synthesis of silylboranes (this work)

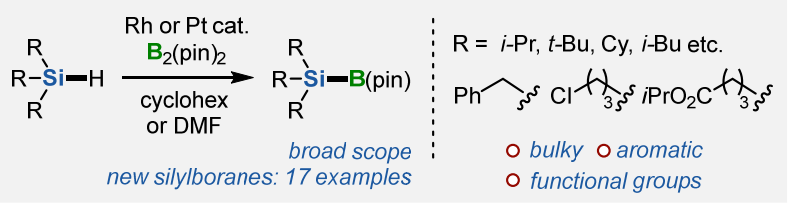

In 2008, the group of Hartwig developed an alternative iridium-catalyzed method for the direct borylation of trialkylhydrosilanes with bis(pinacolato)diboron $\left[\mathrm{B}_{2}(\text { pin })_{2}\right]$ to prepare trialkylsilylboranes such as 1d and 1e (Scheme 2b). ${ }^{13}$ Although this approach is useful, sterically hindered silylboranes such as 1f cannot be prepared. In addition, aromatic-group-functionalized trialkylsilylboranes such as $\mathbf{1 g}$ are inaccessible using this procedure due to the competing undesired aromatic $\mathrm{C}-\mathrm{H}$ borylation reactions promoted by the iridium catalyst. ${ }^{14}$ Thus, the development of a more general synthetic route to trialkylsilylboranes is highly desirable.

Herein, we report the development of general synthetic routes to silylboranes via rhodium- or platinum-catalyzed hydrosilane borylation reactions (Scheme $2 \mathrm{c}$ ). Compared to the methodology developed by Hartwig, the present systems show substantially broader substrate scopes and allow access to seventeen new silylboranes that could either not be prepared using previous methods, or only with substantial difficulty. Furthermore, we investigated the preliminary application of these new silylboranes in organic transformations and demonstrated that they can be used as silicon nucleophiles, which are either inaccessible via previously reported methods, or accessible only with substantial difficulty. The present study provides various silicon-based nucleophiles applicable to organic synthesis, and would thus significantly expand the scope of synthesizable organosilicon compounds with distinct properties.

Specifically, we found that the Rh-based catalytic system is particularly useful for the borylation of sterically hindered trialkylsilanes, which provided for the first time an extremely bulky $i$ - $\mathrm{Pr}_{3} \mathrm{Si}$ - type silylborane. Such bulky silyl groups can potentially tune the lipophilicity of drug molecules ${ }^{4}$ and also provide steric protection that may be able to suppress undesirable intermolecular interactions (e.g., $\pi-\pi$ interactions), which could enable the design of new solid-state light-emitting materials. ${ }^{5}$ Furthermore, the bulky silyl groups are crucial for controlling the conformational effect on the photophysical properties of acyclic oligosilanes-based organic materials. ${ }^{15}$ As such, the newly synthesized bulky trialkylsilylboranes can be expected to become important building blocks for introducing bulky silyl groups into valuable synthetic targets.

We also discovered that the Pt-based catalyst shows unprecedentedly high chemoselectivity that allows the synthesis of benzyl-substituted silylboranes, which can be changed to hydroxy groups by oxidation, and various functional-group-containing trialkylsilylboranes and dialkylarylsilylboranes in good yield. The newly synthesized functional-group-containing silylboranes can be expected to provide rapid and efficient synthetic routes to novel silicon-based compounds with interesting biological activity ${ }^{4}$ or photophysical properties ${ }^{5,15}$ that are unavailable via the conventional electrophilic silylation approach. ${ }^{1}$

\section{RESULTS AND DISCUSSION}

We initially investigated the reactivity of various transitionmetal catalysts in the $\mathrm{Si}-\mathrm{H}$ borylation of trialkylsilanes with $\mathrm{B}_{2}$ (pin)2. ${ }^{16,17}$ We discovered that Rh- and Pt-based catalysts effectively promote the borylation of the $\mathrm{Si}-\mathrm{H}$ bond in trialkylsilanes. Further optimization of the reaction conditions revealed that $[\mathrm{Rh}(\mathrm{OMe})(\mathrm{cod})]_{2} / \mathrm{ICy}(\mathrm{ICy}: 1,3$-dicyclohexylimidazol-2-ylidene) and $\mathrm{Pt} / \mathrm{C}$ (5 wt\% of $\mathrm{Pt}$ on activated carbon) show high catalytic activity (Scheme 3 ; Table S1-S5). ${ }^{18}$ The Rh-based catalyst is especially effective for the borylation of sterically hindered trialkylsilanes such as triisopropylsilane ( $i$ $\mathrm{Pr}_{3} \mathrm{Si}-\mathrm{H}$; 2f), while Hartwig's catalyst system $[\operatorname{Ir}(\mathrm{OMe})(\mathrm{cod})]_{2} / \mathrm{dtbpy}$ did not promote the reaction (Scheme 3, top). The Pt-based catalyst enables the unprecedented chemoselective $\mathrm{Si}-\mathrm{H}$ borylation of benzyldimethylsilane $(\mathbf{2 g})$ without the formation of any aromatic $\mathrm{C}-\mathrm{H}$ borylation products. Conversely, $[\operatorname{Ir}(\mathrm{OMe})(\operatorname{cod})]_{2} /$ dtbpy furnishes $\mathrm{C}-\mathrm{H}$ borylation byproducts, while the desired silylborane is not observed (Scheme 3 , bottom). We also tested the Rh- and Pt-based catalysts under Hartwig's stoichiometry (silane: 4.0 equiv.; $\mathrm{B}_{2}(\text { pin) })_{2}$ : 1.0 equiv. $)^{13}$ and found that both our catalysts exhibit superior performance to those in Hartwig's study (Scheme S1). Notably, silylboranes $\mathbf{1 f}$ and $\mathbf{1 g}$ show high stability toward air and moisture and can be isolated by flash column chromatography on silica gel.

Scheme 3. Discovery of Rh- and Pt-based Catalytic Systems for the Si-H Borylation of Trialkylsilanes. ${ }^{a-c}$ 
$\overbrace{2 f}^{i-H}+$

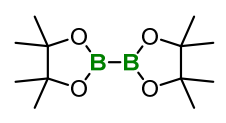

3 (2.5 equiv)
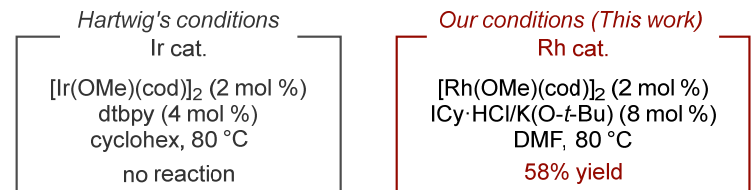

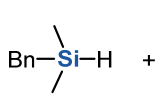

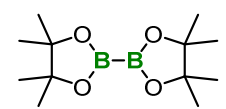

3 (2.5 equiv)

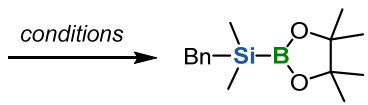

$1 \mathrm{~g}$
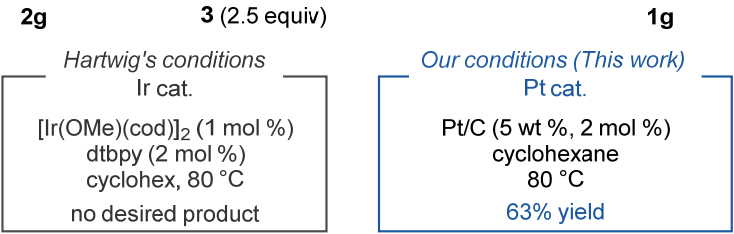

To explore the scope of the present Rh- and Pt-catalyzed Si$\mathrm{H}$ borylations, a variety of hydrosilanes were tested (Table 1). The corresponding Ir-catalyzed borylations were also explored to compare the reactivity of the Ir-, Rh-, and Pt-based catalysts. ${ }^{19}$ Initially, we examined the borylation of sterically hindered trialkylsilanes (Table 1, top row). The reaction of $\mathbf{2} \mathbf{f}$ using the Rh-based catalyst proceeded smoothly to give the desired silylborane $1 \mathrm{f}$ in $58 \%$ yield. Furthermore, we confirmed that the reaction of $\mathbf{2 f}$ on the $5 \mathrm{mmol}$ scale also produced $\mathbf{1 f}$ in good yield. ${ }^{20}$ The use of Pt/C resulted in a lower yield of $\mathbf{1 f}(20 \%)$, while the Ir-based catalyst did not transform $\mathbf{2 f}$. The sterically less hindered $t-\mathrm{BuMe}_{2} \mathrm{Si}-\mathrm{H}(\mathbf{2 h})$ is effectively borylated using the Rh- and Pt-based catalysts to furnish the corresponding products in high yield, while the Ir-based catalyst furnishes only a trace amount of the product (Rh: 87\%; Pt: 78\%; Ir: 7\%) under these conditions. These results demonstrate that $[\mathrm{Rh}(\mathrm{OMe})(\mathrm{cod})]_{2} / \mathrm{ICy}$ is especially effective for the borylation of sterically hindered trialkylsilanes. The reaction of tricyclohexylsilane (2i) with the Rh-based catalyst also produced $\mathbf{1 i}$ $(30 \%)$. The molecular structure of $\mathbf{1 i}$ was confirmed unambiguously by a single-crystal $\mathrm{x}$-ray diffraction analysis (Figure 1, right side). The thus developed $\mathrm{Rh}$-catalysis conditions were also applied to trialkylsilanes bearing $\beta$-branched alkyl groups $(\mathbf{2 j}-\mathbf{2 m})$ or a methoxy group $(\mathbf{2 n})(\mathbf{1 j}: \mathbf{7 3 \%} ; \mathbf{1 k}$ : 75\%; 11: $20 \%$; 1m: $52 \%$; $1 \mathrm{n}: 50 \%$ ). The twofold $\mathrm{Si}-\mathrm{H}$ borylation of $2 \mathrm{o}$ provided the corresponding product (10) in excellent yield (86\%). Additionally, we confirmed that the bulky trialkylsilylboranes $\mathbf{1 i}-\mathbf{1 m}$ and $\mathbf{1 0}$ cannot be synthesized using the Ir-based catalyst.

Table 1. Substrate Scope of Si-H Borylations using the Rhand Pt-based Catalysts.

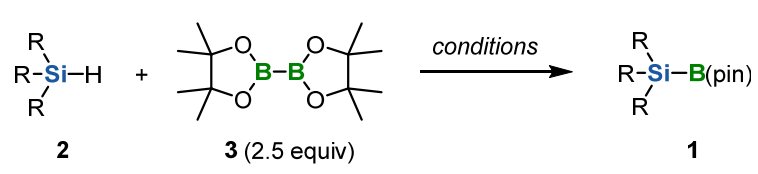

[Rh]: $[\mathrm{Rh}(\mathrm{OMe})(\mathrm{cod})]_{2}(1 \mathrm{~mol} \%), \mathrm{ICy} \cdot \mathrm{HCl} / \mathrm{K}(\mathrm{O}-\mathrm{t}-\mathrm{Bu})(4 \mathrm{~mol} \%), \mathrm{DMF}, 80^{\circ} \mathrm{C}$ [Pt]: Pt/C (5 wt \%, $2 \mathrm{~mol} \%)$, cyclohexane, $80^{\circ} \mathrm{C}$

[Ir]: $[\operatorname{lr}(\mathrm{OMe})(\mathrm{cod})]_{2}(1 \mathrm{~mol} \%)$, dtbpy $(2 \mathrm{~mol} \%)$, cyclohexane, $80^{\circ} \mathrm{C}$

sterically hindered trialkylsilylboranes

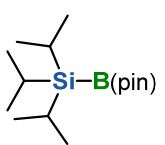

$1 f$

[Rh]: $58 \%^{b}$, [Pt]: $20 \%^{d}$ [Ir]: $0 \%{ }^{\mathrm{C}}$

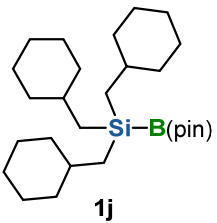

[Rh]: $73 \%^{b},[\mathrm{Ir}]: 0 \%^{c}$

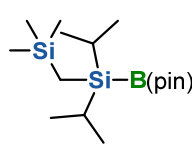

$1 \mathrm{~m}$

[Rh]: $52 \%^{b}$, [Ir]: $0 \%{ }^{\mathrm{c}}$

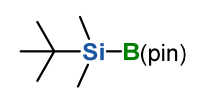

$1 \mathrm{~h}$
[Rh]: $78 \%(87 \%)$ [Pt]: $56 \%$ (78\%), [Ir]: (7)\%

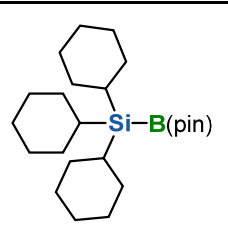

$1 \mathrm{i}$ phenyl- and functional-group-containing trialkylsilylboranes

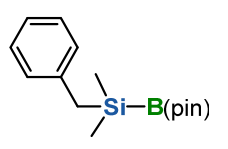

$1 \mathrm{~g}$

[Pt]: 63\%, [Rh]: trace [Ir]: $0 \%$

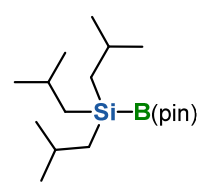

$1 \mathrm{k}$

[Rh]: $75 \%^{b},[\mathrm{Ir}]: 0 \%^{c}$

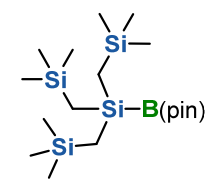

11

[Rh]: $20 \%^{b}$

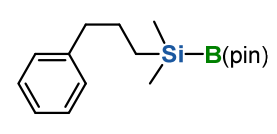

$1 g^{\prime}$

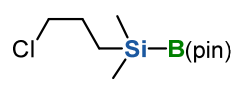

$1 \mathrm{p}$

Pt]: 50\% (89\%) Rh]: (31)\%, [Ir]: (39)\%

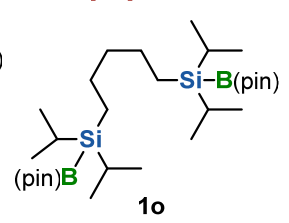

[Rh]: $86 \%,[\mathrm{Ir}]: 0 \%$
[Pt]: 52 (60)\%, [Ir]: (22)\%

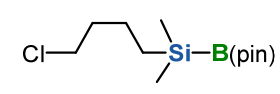

$1 \mathbf{p}^{\prime}$

[Pt]: 50\% (68\%), [Ir]: (9)\% simple trialkylsilylboranes

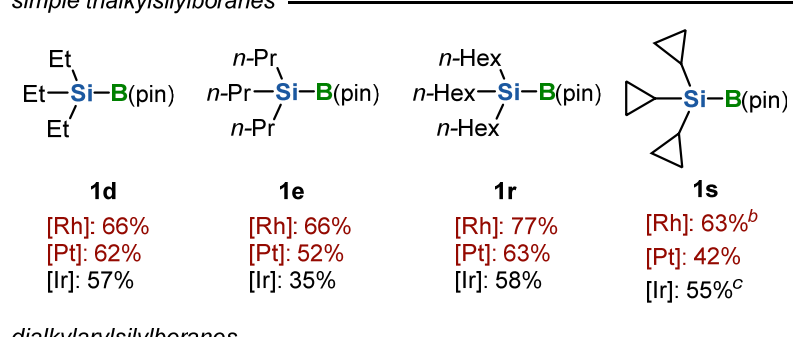

dialkylarylsilylboranes

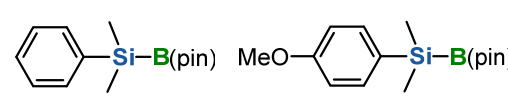

$1 \mathbf{t}$

Pt]: $46 \%(57 \%)^{f}$

[Rh]: (13\%), [Ir]: 0\%

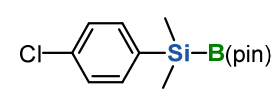

$1 v$

Pt]: $38 \% d, f$
${ }^{a}$ Conditions for the Rh-based catalytic system: $2(0.5 \mathrm{mmol}), 3$ (1.25 mmol), [Rh(OMe)(cod) $]_{2}(0.005 \mathrm{mmol})$, and $\mathrm{ICy} \cdot \mathrm{HCl} / \mathrm{K}(\mathrm{O}-$ 
$t$-Bu) $(0.02 \mathrm{mmol})$ in DMF $(0.5 \mathrm{~mL})$ at $80{ }^{\circ} \mathrm{C}$; conditions for the Pt-based catalytic system: 2 (0.5 mmol), $3(1.25 \mathrm{mmol})$, and Pt/C $(5 \mathrm{wt} \% \mathrm{Pt}, 0.01 \mathrm{mmol})$ in cyclohexane $(0.5 \mathrm{~mL})$ at $80{ }^{\circ} \mathrm{C}$; conditions for the Ir-based catalytic system: $2(0.5 \mathrm{mmol}), 3(1.25 \mathrm{mmol})$, $[\operatorname{Ir}(\mathrm{OMe})(\mathrm{cod})]_{2}(0.005 \mathrm{mmol})$, and dtbpy $(0.01 \mathrm{mmol})$ in cyclohexane $(0.5 \mathrm{~mL})$ at $80^{\circ} \mathrm{C}$. Isolated yields are given. $\mathrm{GC}$ yields are shown in parentheses. ${ }^{b}$ The reaction was carried out using $[\mathrm{Rh}(\mathrm{OMe})(\mathrm{cod})]_{2}(2 \mathrm{~mol} \%)$ and $\mathrm{ICy} \cdot \mathrm{HCl} / \mathrm{KO}^{t} \mathrm{Bu}(8 \mathrm{mo} 1 \%) .{ }^{c} \mathrm{The}$ reaction was carried out using $[\operatorname{Ir}(\mathrm{OMe})(\mathrm{cod})]_{2}(2 \mathrm{~mol} \%)$ and dtbpy (4 mol \%). ${ }^{d}$ The reaction was carried out using $20 \mathrm{~mol} \%$ of $\mathrm{Pt} / \mathrm{C}(5 \mathrm{wt} \% \mathrm{Pt}) .{ }^{e} \mathrm{The}$ borylation was performed using 2 ( $1.5 \mathrm{mmol}$, 3.0 equiv) and 3 ( $0.5 \mathrm{mmol}, 1.0$ equiv). ${ }^{f}$ The borylation was performed at the $1.0 \mathrm{mmol}$ scale.

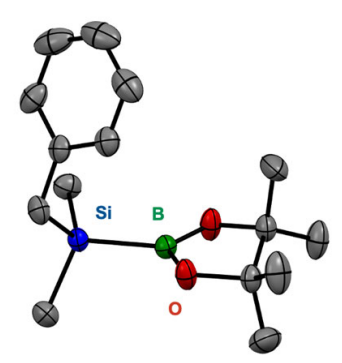

$1 \mathrm{~g}$

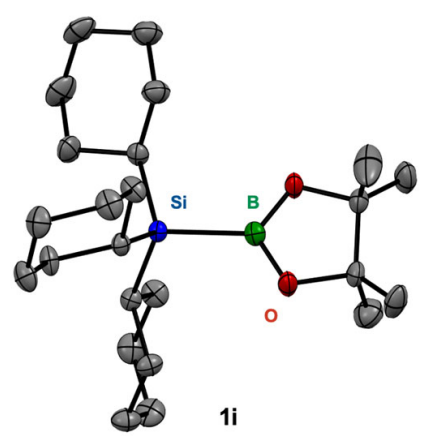

Figure 1. Molecular structures of $\mathbf{1 g}$ and $\mathbf{1 i}$ with thermal ellipsoids at $50 \%$ probability. Hydrogen atoms are omitted for clarity; color code: gray $=$ carbon; green $=$ boron; blue $=$ silicon; red $=$ oxygen .

We then investigated the synthesis of functional-group-containing trialkylsilylboranes (Table 1, middle row). Using Pt/C, the aromatic-functionalized benzyldimethylsilane $\mathbf{2 g}$ was efficiently converted into the desired silylborane (1g) without any side reactions $(63 \%)$. In contrast, $[\operatorname{Ir}(\mathrm{OMe})(\mathrm{cod})]_{2} / \mathrm{dtbpy}$ led to $\mathrm{C}-\mathrm{H}$ borylation of the phenyl group, while $[\mathrm{Rh}(\mathrm{OMe})(\mathrm{cod})]_{2} / \mathrm{ICy}$ furnished a mixture of the $\mathrm{Si}-\mathrm{H}$ and $\mathrm{C}-$ $\mathrm{H}$ borylation products. ${ }^{13,21}$ The molecular structure of $\mathbf{1 g}$ was determined by single-crystal $\mathrm{x}$-ray diffraction analysis (Figure 1 , left). We also confirmed that the reaction of $2 \mathrm{~g}$ on the $5 \mathrm{mmol}$ scale produced $\mathbf{1 g}$ in good yield. ${ }^{20}$ These Pt-catalyzed conditions were also applicable to trialkylsilanes containing phenyl $\left(\mathbf{2} \mathbf{g}^{\prime}\right)$, chloro (2p, $\left.\mathbf{2} \mathbf{p}^{\prime}\right)$, and ester groups (2q), which furnished the corresponding products in good yield $\left(\mathbf{1 g}^{\prime}: 60 \%\right.$; 1p: $89 \%$; 1p': 68\%; 1q: 62\%). Simple, small trialkylsilanes provided the corresponding products in high yield using the Ir-, Rh-, and Ptbased catalysts (Table 1, lower row), whereby linear- or cyclicalkyl-group-substituted hydrosilanes 2d, 2e, 2r, and 2s effectively underwent the borylation. It should be noted here that the silylboranes (1d-1s) shown in Table 1 can be isolated by flash column chromatography on silica gel.

Furthermore, we found that the Pt-catalyzed reactions of dimethylarylsilanes that bear phenyl (2t), 4- $\mathrm{MeOC}_{6} \mathrm{H}_{4}(\mathbf{2 u})$, and 4- $\mathrm{ClC}_{6} \mathrm{H}_{4}(\mathbf{2 v})$ groups proceeded smoothly to give the desired dimethylarylsilylboranes (1t-1v) in moderate yield (1t: 46\%; 1u: $41 \%$; 1v: $38 \%$ ). The lower yields of these dialkylarylsilylboranes than the yields of trialkylsilylboranes are mainly due to their instability in the isolation process. The Ir-based catalyst did not provide the desired product (1t) due to competing undesired aromatic $\mathrm{C}-\mathrm{H}$ borylation reactions. ${ }^{14}$ Notably, these are the first examples of dialkylarylsilylboranes that bear methoxy(1u) or chloro groups (1v); such compounds cannot be directly prepared via the conventional method using an alkali metal. As the 4- $\mathrm{MeO}-\mathrm{C}_{6} \mathrm{H}_{4} \mathrm{Me}_{2} \mathrm{Si}$ group is more reactive than the $\mathrm{PhMe}_{2} \mathrm{Si}$ group in Tamao-Flemming oxidations, ${ }^{22}$ silylborane $\mathbf{1 u}$ will most likely find widespread applications in organic synthesis.

Based on previous studies of Rh-catalyzed $\mathrm{C}-\mathrm{H}$ borylations, we propose a plausible reaction mechanism for the present $\mathrm{Rh}$ catalyzed Si-H borylation (Scheme 4A). ${ }^{14}$ The ICy-Rh(I)(OR) complex generated in situ could react initially with $\mathrm{B}_{2}$ (pin) $)_{2}$ to produce borylrhodium(I) complex $\mathbf{A}$ as the catalytically active species. Subsequent $\mathrm{Si}-\mathrm{H}$ bond cleavage with $\mathbf{A}$ would proceed to afford complex $\mathbf{B}$, which would then produce complex $\mathbf{C}$ via $\sigma$-bond metathesis. Finally, the reductive elimination of silylborane 1 would regenerate borylrhodium(I) complex A. On the basis of previous studies on Pt-catalyzed silylation reactions using hydrosilanes, we propose a feasible Pt-catalyzed cycle (Scheme 4A'). ${ }^{16}$ The oxidative addition of Pt on a metal cluster in $\mathrm{Pt} / \mathrm{C}$ to the $\mathrm{Si}-\mathrm{H}$ bond in $\mathbf{2}$ would initially produce silylhydridoplatinum(II) intermediate $\mathbf{B}^{\prime}$, which would subsequently react with $\mathrm{B}_{2}$ (pin) $)_{2}$ to form complex $\mathbf{C}^{\prime}$. Finally, the reductive elimination of silylborane $\mathbf{1}$ would lead to the regeneration of the active $\operatorname{Pt}(0)$ species.

Scheme 4. Proposed Reaction Mechanisms for the Rh- and Pt-Catalyzed Si-H Borylation Reactions.

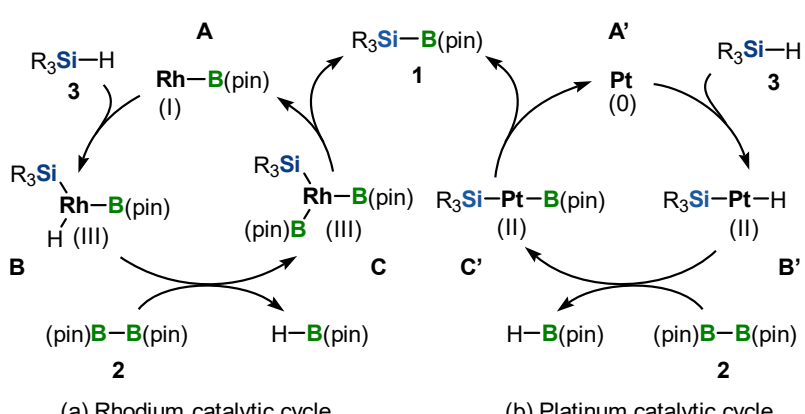

Subsequently, we turned our attention to the preliminary investigation on application of the obtained trialkylsilylboranes as silicon nucleophiles to demonstrate their utility in organic synthesis (Scheme 5). Initially, we investigated several transitionmetal-catalyzed silylation reactions using the newly synthesized trialkylsilylboranes (Scheme 5a-5d).

A copper(I)-catalyzed conjugate addition of a silyl group to 2-cyclohexen-1-one (4), which was first reported by Hoveyda using $\mathrm{PhMe}_{2} \mathrm{Si}-\mathrm{B}$ (pin) (1a), proceeded effectively with bulky trialkylsilylboranes to afford the respective silylation products in high yield (Scheme 5a; 5a: 89\%; 5b: 82\%). ${ }^{23}$ The newly synthesized functionalized trialkylsilylboranes $\mathbf{1 g}$ and $\mathbf{1 p}$ could also be used as silylation reagents to produce the corresponding products in high yield (5c: $82 \%$; 5d: $90 \%)$. In this reaction, the new trialkylsilylboranes showed high reactivity comparable to that of 1a.

Then, we investigated the copper (I)-catalyzed radical silylation of alkyl iodides, which has been reported by Oestreich for 1a and $\mathrm{Et}_{3} \mathrm{Si}-\mathrm{B}$ (pin) (1d). ${ }^{24}$ We examined the applicability of our new functionalized and bulky trialkylsilylboranes in this reaction (Scheme 5b). Iodocyclohexane 6 underwent silylation with trialkylsilylboranes $\mathbf{1 g}$ or $\mathbf{1 p}$ to give the corresponding silylation products in moderate yield (7a: $54 \%$; $7 \mathbf{b}: 51 \%)$. However, bulky trialkylsilylborane $\mathbf{1 f}$ could not be applied to this reaction (Table S7). 


\section{Scheme 5. Use of Trialkylsilylboranes as Silicon Nucleophiles in Organic Synthesis. ${ }^{a}$}

a. Cu-catalyzed silyl conjugate addition
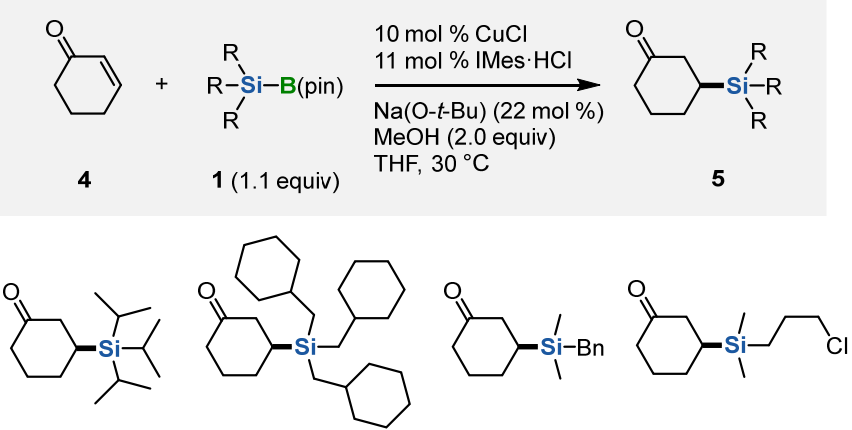

5a, $89 \%$

5b $82 \%$

$5 c, 82 \%$

$5 d, 90 \%$

d. Pd-catalyzed silylation of aryl halide<smiles>CCNC(=O)c1ccc(Br)cc1</smiles>

10

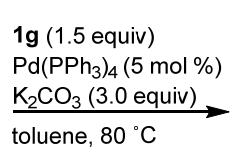
toluene, $80^{\circ} \mathrm{C}$<smiles>CCNC(=O)c1ccc(O)cc1</smiles><smiles>CCNC(=O)c1ccc([Si](C)(C)Cc2ccccc2)cc1</smiles>

$11,85 \%$

$$
\begin{aligned}
& \text { 1) TBAF, THF, rt } \\
& \text { 2) } \mathrm{H}_{2} \mathrm{O}_{2}, \mathrm{KHCO}_{3}, \\
& \mathrm{MeOH}, \mathrm{rt}
\end{aligned}
$$

b. Cu-catalyzed cross-coupling of alkyl iodide

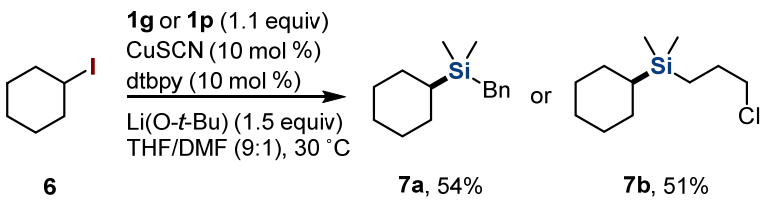

c. Ni-catalyzed cross-coupling of aryl methyl ether

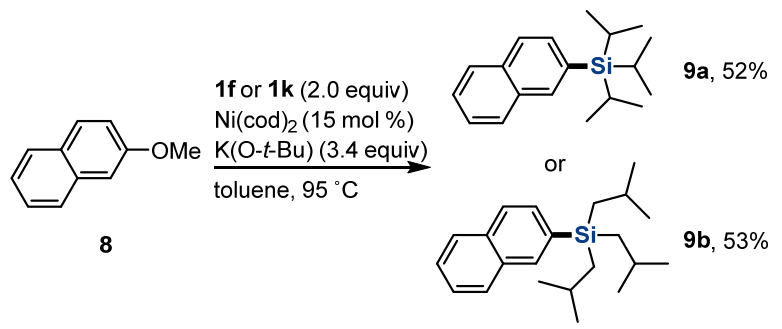

e. NHC-catalyzed silyl conjugate addition

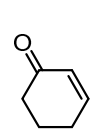

$1 \mathrm{~g}$ (1.1 equiv) SIMes. $\mathrm{HCl}(5 \mathrm{~mol} \%)$ $\underset{\mathrm{THF} / \mathrm{H}_{2} \mathrm{O}(1: 1), 30^{\circ} \mathrm{C}}{\stackrel{\mathrm{DBU}(20 \mathrm{~mol} \%)}{\longrightarrow}}$

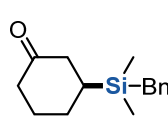
$\Theta$ $\mathrm { Cl } \longdiv { N } \oplus$

4

SIMes $\cdot \mathrm{HCl}$

f. Introduction of various functionalized trialkylsilyl groups

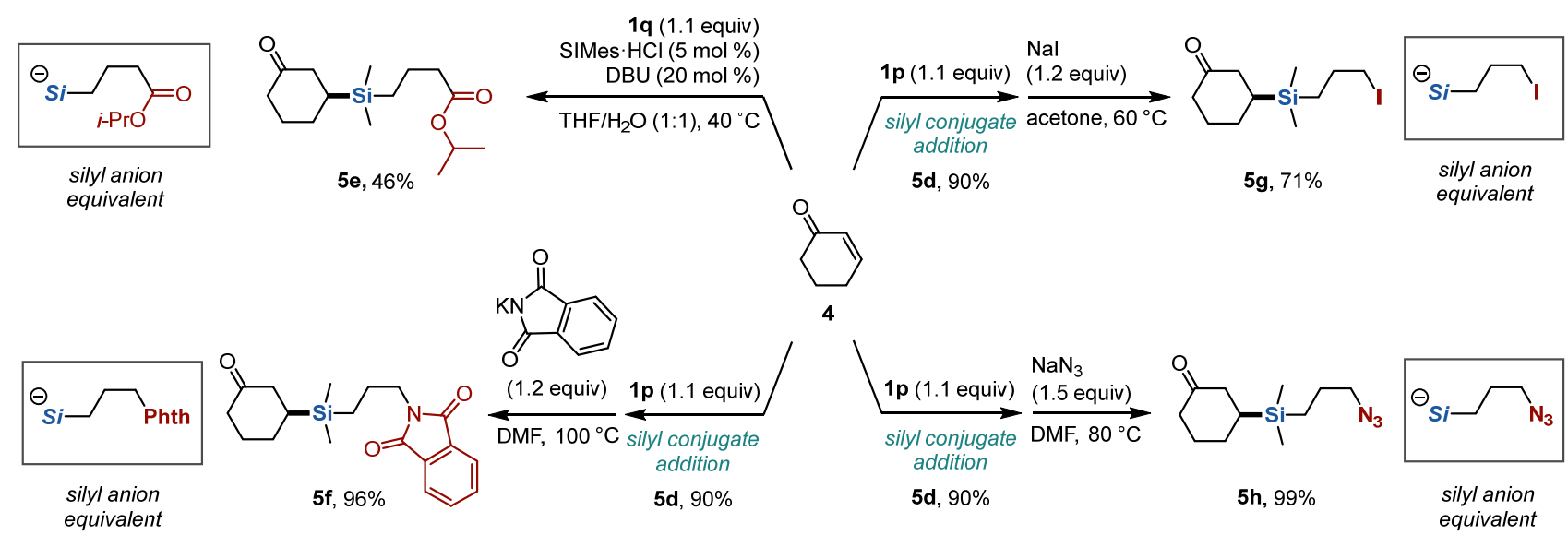

${ }^{a}$ Isolated yields are given. For details of the reaction conditions, see the Supporting Information.

Sterically hindered trialkylsilylboranes $\mathbf{1 f}$ and $\mathbf{1 k}$ were successfully applied to the Ni-catalyzed silylation of aryl methyl ethers, which has been reported by Martin using less bulky 1d (Scheme $5 \mathrm{c}) .^{8 \mathrm{~b}}$ The reaction of 2-methoxynaphthalene $(\mathbf{8})$ with $\mathbf{1 f}$ or $\mathbf{1 k}$ furnished the corresponding silylation products in moderate yield (9a: $52 \%$; 9b: 53\%); these yields are lower than that achieved using 1d due to steric hindrance. The use of benzylfunctionalized $1 \mathrm{~g}$ resulted in a complex product mixture (Table S8).

The Pd-catalyzed cross-coupling of aryl bromide $\mathbf{1 0}$ with $\mathbf{1 g}$ proceeded effectively to give the corresponding product in good yield (Scheme 5d; 11: 85\%). ${ }^{25}$ However, bulky trialkylsilylboranes $1 \mathbf{f}$ and $1 \mathbf{k}$ did not provide any product in this reaction (Table S9). The $\mathrm{BnMe}_{2} \mathrm{Si}$ group in $\mathbf{1 1}$ can be converted into a hydroxy group by a Tamao-Fleming oxidation, which quantitatively affords the phenol derivative $12(94 \%){ }^{26}$

The newly synthesized trialkylsilylboranes can also be applied in base-mediated silylation reactions. NHC-catalyzed silyl conjugate addition to 2-cyclohexen-1-one 4 , which was reported by Hoveyda and co-workers using 1a, proceeded effectively with trialkylsilylborane $\mathbf{1 g}$ to produce the corresponding product $(\mathbf{5 c})$ in good yield $(57 \%$; Scheme $5 \mathrm{e})$. $^{27}$

We then investigated the synthesis of multi-functionalized organosilicon compounds that have been difficult to access using previously reported procedures. Ester-functionalized trialkylsilylborane 1q successfully afforded silylation product $\mathbf{5 e}$ in moderate yield (46\%; Scheme 5f). Subsequently, further transformation of the chloro group in $\mathbf{5 d}$, which was obtained via 
copper(I)-catalyzed silyl conjugate addition to $\mathbf{4}$ with $\mathbf{1 p}$, was investigated (Scheme 5f). Compound $\mathbf{5 d}$ was easily converted into phthalimide $5 \mathrm{f}$ in $96 \%$ yield by reaction with the phthalimide potassium salt. The reaction of $\mathbf{5 d}$ with sodium iodide produced the corresponding iodination product $(\mathbf{5 g})$ in $71 \%$ yield, and $\mathbf{5 d}$ underwent azidation with sodium azide to quantitatively furnish $\mathbf{5 h}$. Thus, the present procedures provide unprecedented access to silyl anion equivalents that bear various functionalized groups, including " $\mathrm{SiCH}_{2} \mathrm{CH}_{2} \mathrm{CH}_{2} \mathbf{C O}_{2} \mathbf{R}$ ", "- $\mathrm{SiCH}_{2} \mathrm{CH}_{2} \mathrm{CH}_{2} \mathbf{I}$ ", "- $\mathrm{SiCH}_{2} \mathrm{CH}_{2} \mathrm{CH}_{2}$ NPhth", and "$\mathrm{SiCH}_{2} \mathrm{CH}_{2} \mathrm{CH}_{2} \mathrm{~N}_{3}$ " (Scheme 5f).

Oligosilanes have attracted research interest due to their unique optical, electronic, and photoreactive properties, which originate from their silicon-silicon bonds. ${ }^{15}$ Thus, we decided to focus on silicon-silicon cross-coupling reactions of silyl electrophiles using the newly synthesized trialkylsilylboranes in the presence of an activating nucleophile (Scheme 6 and Table S10). ${ }^{28}$ Silicon-silicon bonds are generally formed by Wurtztype condensations of a halosilane in the presence of an alkali metal or the reaction of a silyl anion with a silyl electrophile. ${ }^{29}$ However, in these methods, the synthesis of all-alkyl-substituted unsymmetrical oligosilanes is especially challenging due to the limitations in the generation of silyl anions. On the other hand, reactions of silylboranes with activating nucleophiles can easily produce various silyl anion equivalents. Therefore, we envisioned that various asymmetrically substituted oligosilanes that are difficult to access using previously reported methods could be synthesized using trialkylsilylboranes prepared by Rhor Pt-catalyzed $\mathrm{Si}-\mathrm{H}$ borylation reactions. Indeed, the reactions of bulky trialkylsilylboranes $\mathbf{1 f}, \mathbf{1} \mathbf{k}$, and $\mathbf{1 h}$ proceeded effectively to afford the corresponding desired disilanes (13a: 73\%; 13b: $92 \%$; 13c: 91\%; 13d: 77\%) in high yield. Moreover, the chloro-functionalized silylborane $1 \mathbf{p}$ could be applied to the $\mathrm{Si}-$ Si coupling reaction with $i-\mathrm{Pr}_{3} \mathrm{Si}-\mathrm{OTf}$ to furnish $\mathbf{1 3 e}$ in $78 \%$ yield. Dichlorosilanes and -disilanes also engaged in this reaction to give the corresponding tri- or tetrasilanes in good yield. The unsymmetrical trisilane 13f was obtained in low yield $(35 \%)$ using $\mathbf{1 f}$ and $\mathbf{1 h}$. Two $i-\mathrm{Pr}_{3} \mathrm{Si}$ - or tricyclohexylsilylgroups could be introduced into dichlorodisilane or -silane to give $\mathbf{1 3 g}$ and $\mathbf{1 3 h}$ in $61 \%$ and $55 \%$ yield, respectively, when 2.0 equivalents of $\mathbf{1 f}$ or $\mathbf{1 i}$ were used. These di-, tri-, and tetrasilanes have not been synthesized before, and their controlled synthesis via previously reported methods should be very difficult. In addition, the sterically hindered alkyl substituents are known to be important for controlling the conformational effect on the photophysical properties of acyclic oligosilanes-based organic materials, which suggests high potential utility of such trialkylsilylboranes with bulky alkyl substituents. ${ }^{5,15}$ The molecular structure of $13 \mathrm{~h}$ was confirmed by single-crystal $\mathrm{x}$-ray diffraction analysis.

Scheme 6. Oligosilane Synthesis by Silicon-Silicon CrossCoupling Using Trialkylsilylboranes. ${ }^{a}$

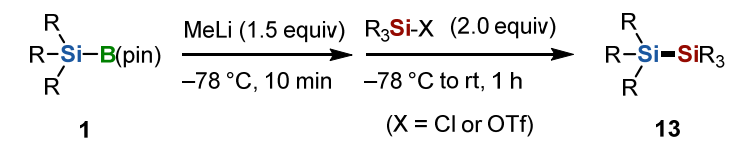

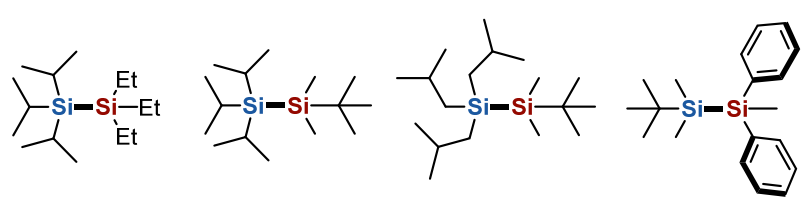

$\begin{array}{llll}13 a, 73 \% & 13 b, 92 \% & 13 c, 91 \% & 13 d, 77 \%\end{array}$

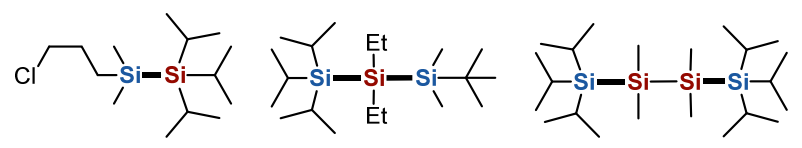

$13 \mathbf{e}, 78 \% \quad \mathbf{1 3 f}, 35 \%^{b} \quad \mathbf{1 3 g}, 61 \%^{c}$

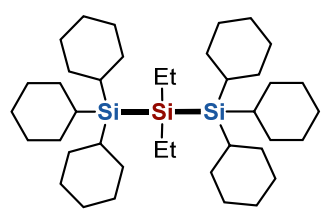

$13 \mathrm{~h}, 55 \%^{c}$

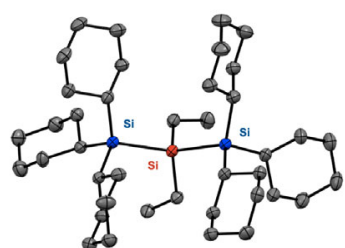

$X$-ray structure of $13 \mathrm{~h}$
${ }^{a}$ Conditions: 1 (0.2 mmol), $\mathrm{MeLi}(1.1 \mathrm{M}$ in Et $2 \mathrm{O}, 0.27 \mathrm{~mL})$, silyl electrophile $(\mathrm{X}=\mathrm{Cl}$ or OTf, $0.4 \mathrm{mmol})$ in THF $(1.0 \mathrm{~mL})$. Percentage values refer to isolated yields. ${ }^{b}$ Conditions: $\mathbf{1 f}(0.2 \mathrm{mmol}), \mathbf{1 h}$ $(0.2 \mathrm{mmol}), \mathrm{MeLi}\left(1.1 \mathrm{M}\right.$ in $\left.\mathrm{Et}_{2} \mathrm{O}, 0.44 \mathrm{~mL}\right), \mathrm{Et}_{2} \mathrm{SiCl}_{2}(0.2 \mathrm{mmol})$ in THF (3.0 mL). ${ }^{c}$ Conditions: $1(0.4 \mathrm{mmol}), \mathrm{MeLi}\left(1.1 \mathrm{M}\right.$ in $\mathrm{Et}_{2} \mathrm{O}$, $0.41 \mathrm{~mL})$, silyl electrophile $(0.2 \mathrm{mmol})$ in THF $(2.0 \mathrm{~mL})$.

Finally, we conducted in situ ${ }^{11} \mathrm{~B}\left\{{ }^{1} \mathrm{H}\right\}$ and ${ }^{29} \mathrm{Si}\left\{{ }^{1} \mathrm{H}\right\}$ NMR experiments to confirm the formation of a trialkylsilyl anion equivalent in the reaction of a silylborane with methyl lithium (MeLi) (Figure 2). Kawachi and Tamao have reported the formation of $\mathrm{Ph}_{3} \mathrm{SiLi}$ from the reaction of $\mathrm{Ph}_{3} \mathrm{Si}-\mathrm{B}$ (pin) with $\mathrm{MeLi}^{28}{ }^{28}$ whereas our group and that of Shibata have reported that the reaction of $\mathrm{PhMe}_{2} \mathrm{Si}-\mathrm{B}$ (pin) (1a) or $\mathrm{Et}_{3} \mathrm{Si}-\mathrm{B}$ (pin) (1b) with $\mathrm{K}(\mathrm{O}-t-\mathrm{Bu})$ produces the corresponding adduct with an $s p^{3}$ boronate structure. ${ }^{8 \mathrm{a}, 30}$ To the best of our knowledge, the generation of a trialkylsilyllithium via the reaction of a trialkylsilylborane with an alkyl lithium compound has not been reported. In the present study, NMR results revealed that $i-\mathrm{Pr}_{3} \mathrm{SiLi}(\mathbf{1 5})$ is the main product generated in the reaction of $\mathbf{1 f}$ with MeLi (Figure $2 \mathrm{~A}$ and $\mathrm{B}$ ). Treatment of $\mathbf{1 f}$ with 1.5 equivalents of MeLi in THF- $d_{8}$ led to two new ${ }^{11} \mathrm{~B}$ signals: A large signal consistent with $\mathrm{Me}-\mathrm{B}(\mathrm{pin})(\mathbf{1 5}, \delta 33.2 \mathrm{ppm})$, which was assumed to be formed via a heterolytic cleavage of the $\mathrm{Si}-\mathrm{B}$ bond in $\mathbf{1 f}$, and a small signal ( $\delta 8.2 \mathrm{ppm})$ that was attributed to the $s p^{3}$ boron atom of 14, which adopts a tetrahedral coordination geometry. ${ }^{8 \mathrm{a}}$, ${ }^{28-32}$ Furthermore, a new ${ }^{29} \mathrm{Si}$ signal ( $\left.\delta 14.7 \mathrm{ppm}\right)$, which was attributed to silyllithium $15,{ }^{33}$ was detected in the ${ }^{29} \mathrm{Si}\left\{{ }^{1} \mathrm{H}\right\}$ NMR spectrum. The ${ }^{29} \mathrm{Si}-{ }^{7} \mathrm{Li}$ coupling of $\mathbf{1 5}$ was observed at $100{ }^{\circ} \mathrm{C}\left(\delta 11.8 \mathrm{ppm}\right.$, quartet, $J\left[{ }^{29} \mathrm{Si}-{ }^{7} \mathrm{Li}\right]=52 \mathrm{~Hz}$ ) (Figure 2B'). ${ }^{12}$ The ${ }^{29} \mathrm{Si}\left\{{ }^{1} \mathrm{H}\right\}$ NMR signal of the $i-\mathrm{Pr}_{3} \mathrm{Si}-\mathrm{B}(\mathrm{pin}) / \mathrm{MeLi}$ ate complex was not observed, probably due to the presence of the quadrupolar boron atom. ${ }^{31}$ This signal is not consistent with that of $i-\mathrm{Pr}_{3} \mathrm{Si}-\mathrm{H}(\delta 12.1 \mathrm{ppm})$, which can be formed by quenching 15 with $\mathrm{H}_{2} \mathrm{O}$. These results indicate that $\mathbf{1 5}$ is generated in 
situ, which is in agreement with Kawachi's report on the heterolytic cleavage and the formation of silyl anion species for $\mathrm{Ph}_{3} \mathrm{SiLi}_{1}{ }^{28}$ This is the first observation of the generation of the $i$ - $\mathrm{Pr}_{3} \mathrm{SiLi}(\mathbf{1 5})$, which is not accessible by any other methods.

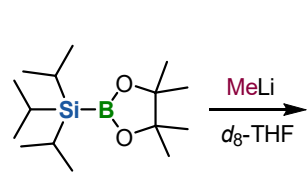

$1 \mathrm{f}$

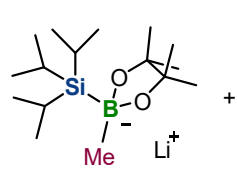

14

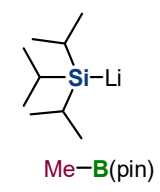

15
${ }^{11}$ B NMR: $\delta 34.5$ ppm
${ }^{11}$ B NMR: $\delta 8.2$ ppm $\quad{ }^{11}$ B NMR: $\delta 33.2$ ppm both detected
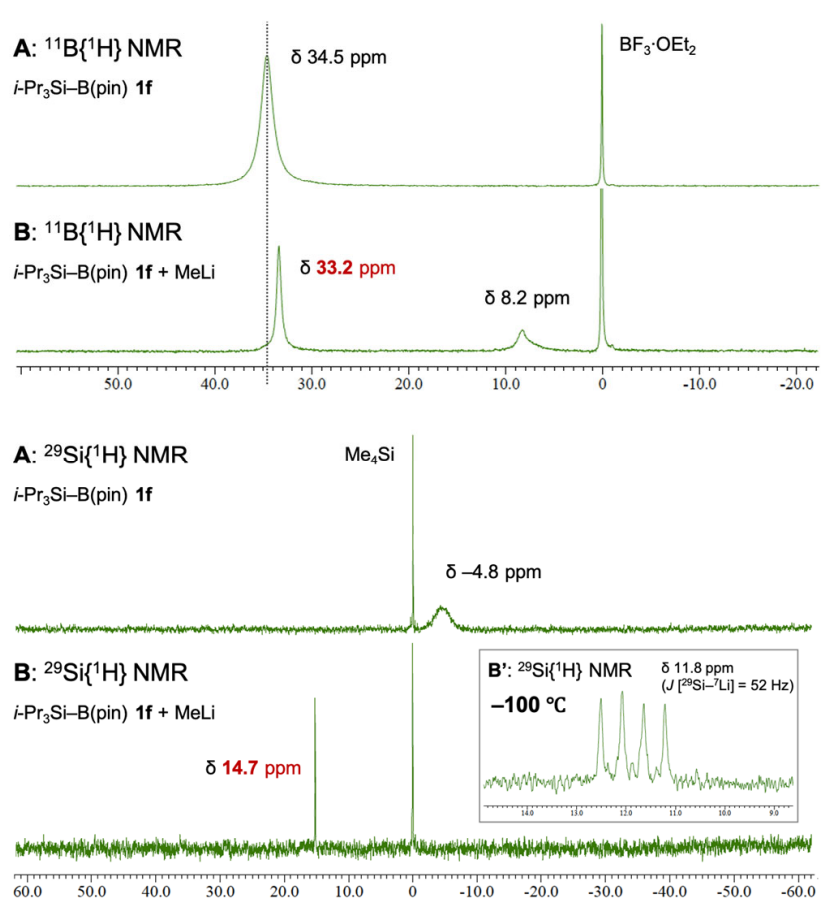

Figure 2. ${ }^{11} \mathrm{~B}\left\{{ }^{1} \mathrm{H}\right\}$ and ${ }^{29} \mathrm{Si}\left\{{ }^{1} \mathrm{H}\right\}$ NMR spectra of the bulky silyllithium compounds obtained from the reaction of trialkylsilylborane 1f with MeLi: (A) $\mathbf{1 f}$; (B) $\mathbf{1 f}(0.1 \mathrm{mmol})$ with $\mathrm{MeLi}(0.15$ $\mathrm{mmol})$ in THF- $d_{8}(0.14 \mathrm{M})$ after stirring for $30 \mathrm{~min}$ at $-78{ }^{\circ} \mathrm{C}$. ${ }^{11} \mathrm{~B}\left\{{ }^{1} \mathrm{H}\right\}$ and ${ }^{29} \mathrm{Si}\left\{{ }^{1} \mathrm{H}\right\}$ NMR analyses were conducted at room temperature. $\mathrm{BF}_{3} \cdot \mathrm{OEt}_{2}$ was used as an external standard to calibrate the ${ }^{11} \mathrm{~B}\left\{{ }^{1} \mathrm{H}\right\}$ NMR spectra, while $\mathrm{Me}_{4} \mathrm{Si}$ was used as an external standard to calibrate the ${ }^{29} \mathrm{Si}\left\{{ }^{1} \mathrm{H}\right\}$ NMR spectra. The ${ }^{29} \mathrm{Si}\left\{{ }^{1} \mathrm{H}\right\}$ NMR spectrum of the mixture of $\mathbf{1 f}(0.1 \mathrm{mmol})$ with $\mathrm{MeLi}(0.15 \mathrm{mmol})$ in THF- $d_{8}(0.14 \mathrm{M})$ analyzed at $-100{ }^{\circ} \mathrm{C}$ is shown in inset $\mathbf{B}$ '.

\section{CONCLUSIONS}

In summary, we have developed new methods for the synthesis of trialkylsilylboranes via rhodium- or platinum-catalyzed direct borylations of hydrosilanes with bis(pinacolato)diboron. The developed conditions provide access to novel classes of trialkylsilylboranes with bulky alkyl or functional groups on the silyl group. Notably, we have successfully synthesized seventeen new silylboranes that are difficult to prepare using previously reported methods. In addition, we have demonstrated the utility of these silylboranes as silicon nucleophiles in subsequent organic transformations. These results demonstrate that the developed methodology significantly expands the boundaries of silylborane chemistry and the scope of accessible organosilicon compounds. Beyond the immediate utility of these

protocols, the newly synthesized silicon nucleophiles could inspire the development of efficient methods for providing new silicon-containing bioactive molecules and organic materials with distinct properties. ${ }^{4,5,15}$ Further applications of these silylboranes and investigations directed toward the elucidation of the reaction mechanism are in progress and will be reported in due course.

\section{ASSOCIATED CONTENT}

\section{Supporting Information}

The Supporting Information is available free of charge via the internet at http://pubs.acs.org.

Experimental procedures and data (PDF)

$\mathrm{X}$-ray crystallographic data for $\mathbf{1 g}, \mathbf{1 i}$, and $\mathbf{1 3 h}(\mathrm{CIF})$

\section{AUTHOR INFORMATION}

\section{Corresponding Author}

*hajito@eng.hokudai.ac.jp

*kbt@eng.hokudai.ac.jp

\section{Notes}

The authors declare no competing financial interests.

\section{ACKNOWLEDGMENT}

This work was financially supported by the Japan Society for the Promotion of Science (JSPS) via KAKENHI grants 18H03907, 17H06370, and 19K15547, by JST CREST grant JPMJCR19R1, the Program for Leading Graduate Schools, and the Institute for Chemical Reaction Design and Discovery (ICReDD), which has been established by the World Premier International Research Initiative (WPI), MEXT, Japan. We are grateful to Dr. M. Jin and T. Mashimo (Hokkaido University) for their assistance with the X-ray crystallographic analyses. We also thank Dr. Y. Kumaki (High-resolution NMR Laboratory, Faculty of Science, Hokkaido University) for his assistance with NMR measurements. Parts of the computational calculations were performed at the Research Center for Computational Science, Okazaki, Japan.

\section{REFERENCES}

(1) (a) Organosilicon Chemistry: Novel Approaches and Reactions; Hiyama, T., Oestreich, M., Eds.; Wiley-VCH: Weinheim, 2020; (b) Silicon in Organic, Organometallics, and Polymer Chemistry; Brook, M. A. Ed.; Wiley-Interscience Publication, 2000; (c) Cuenca, A. B.; Shishido, R.; Ito, H.; Fernández, E. Transition-metal-free B-B and Binterelement reactions with organic molecules. Chem. Soc. Rev. 2017, 46, 415-430; (d) Yamamoto, E.; Maeda, S.; Taketsugu, T.; Ito, H. Transition-metal-free boryl substitution using silylboranes and alkoxy bases. Synlett 2017, 28, 1258-1267; (e) Oestreich, M.; Hartmann, E.; Mewald, M. Activation of the Si-B interelement bond: mechanism, catalysis, and synthesis. Chem. Rev. 2013, 113, 402-441; (f) Ohmura, T.; Suginome, M. Silylboranes as new tools in organic synthesis. Bull. Chem. Soc. Jpn. 2009, 82, 29-49.

(2) (a) Metal-catalyzed cross-coupling reactions, ed. Meijere, A. and Diederich, F., Ed. Wiley-VCH, Weinheim, 2nd revised edn, 2008; (b) Miyaura, N.; and Suzuki, A. Palladium-catalyzed cross-coupling reactions of organoboron compounds. Chem. Rev., 1995, 95, 2457; (c) Lennox, A. J. J. and Lloyd-Jones, G. C. Selection of boron reagents for Suzuki-Miyaura coupling. Chem. Soc. Rev., 2014, 43, 412; (d) Martin, R. and Buchwald, S. L. Palladium-catalyzed Suzuki-Miyaura crosscoupling reactions employing dialkylbiaryl Phosphine Ligands. Acc. Chem. Res., 2008, 41, 1461.

(3) Hall, D. G., Ed. Boronic Acids: Preparation and Application in Organic Synthesis, Medicine and Materials, 2nd revised ed.; WileyVCH: Weinheim, Germany, 2011. 
(4) For selected examples of silicon-containing bioactive compounds, see: (a) Ramesh, R.; Reddy, D. S. Quest for novel chemical entities through incorporation of silicon in drug scaffolds. J. Med. Chem. 2018, 61, 3779-3798; (b) Minkovich, B.; Ruderfer I.; Kaushansky, A.; Bravo-Zhivotovskii, D.; Apeloig, Y. $\alpha$-Sila-dipeptides: synthesis and characterization. Angew. Chem., Int. Ed. 2018, 57, 1326113265; (c) Liu, B.; Gai, K.; Qin, H.; Liu, X.; Cao, Y.; Lu, Q.; Lu, D.; Chen, D.; Shen, H.; Song, W.; Zhang, Y.; Wang, X.; Xu, H.; Zhang, Y. Design, synthesis and identification of silicon-containing HCV NS5A inhibitors with pan-genotype activity. Eur. J. Med. Chem. 2018, 148, 95-105.

(5) For selected examples of silicon-containing organic materials, see: (a) Namba, T.; Hayashi, Y.; Kawauchi, S.; Shibata, Y.; Tanaka, K. Rhodium-catalyzed cascade synthesis of benzofuranylmethylidenebenzoxasiloles: elucidating reaction mechanism and efficient solidstate fluorescence. Chem.-Eur. J. 2018, 24, 7161-7171; (b) Mouri, K.; Wakamiya, A.; Yamada, H.; Kajiwara, T.; Yamaguchi, S. Ladder distyrylbenzenes with silicon and chalcogen bridges: synthesis, structures, and properties. Org. Lett. 2007, 9, 93-96; (c) Yamada, H.; Xu, C.; Fukazawa, A.; Wakamiya, A.; Yamaguchi, S. Structural modification of silicon-bridged ladder stilbene oligomers and distyrylbenzenes. Macromol. Chem. Phys. 2009, 210, 904-916; (d) Koide, Y.; Urano, Y.; Hanaoka, K.; Terai, T.; Nagano, T. Evolution of group 14 rhodamines as platforms for near-infrared fluorescence probes utilizing photoinduced electron transfer. ACS Chem. Biol. 2011, 6, 600-608.

(6) (a) Seyferth, D.; Kögler, H. P. Preparation of organosilicon-substituted borazenes. J. Inorg. Nucl. Chem. 1960, 15, 99-104; (b) Cowley, A. H.; Sisler, H. H.; Ryschkewitsch, G. E. The chemistry of borazine. III. B-silyl boranzines. J. Am. Chem. Soc. 1960, 82, 501-502.

(7) (a) Suginome, M.; Matsuda, T.; Ito, Y. Convenient preparation of silylboranes. Organometallics 2000, 19, 4647-4649; (b) Ohmura, T.; Masuda, K.; Furukawa, H.; Suginome, M. Synthesis of silylboronic esters functionalized on silicon. Organometallics 2007, 26, 1291-1294.

(8) For recent examples of transition-metal-catalyzed reactions with silylboranes, see: (a) Cui, B.; Jia, S.; Tokunaga, E.; Shibata, N. Defluorosilylation of fluoroarenes and fluoroalkanes. Nat. Commun. 2018, 9, 4393-4400; (b) Zarate, C.; Nakajima, M.; Martin, R. A mild and ligand-free Ni-catalyzed silylation via $\mathrm{C}-\mathrm{OMe}$ cleavage. $J . \mathrm{Am}$. Chem. Soc. 2017, 139, 1191-1197; (c) Guo, L.; Chatupheeraphat, A.; Rueping, M. Decarbonylative silylation of esters by combined nickel and copper catalysis for the synthesis of arylsilanes and heteroarylsilanes. Angew. Chem., Int. Ed. 2016, 55, 11810-11813; (d) Tani, Y.; Yamaguchi, T.; Fujiwara, T.; Terao, J.; Tsuji, Y. Copper-catalyzed silylative allylation of ketones and aldehydes employing allenes and silylboranes. Chem. Lett. 2015, 44, 271-273.

(9) For recent examples of transition-metal-free reactions with silylboranes, see: (a) Morisawa, Y.; Kabasawa, K.; Ohmura, T.; Suginome, M. Pyridine-based organocatalysts for regioselective syn-1,2-silaboration of terminal alkynes and allenes. Asian J. Org. Chem. 2019, 8, 1092-1096; (b) Kojima, K.; Nagashima, Y.; Wang, C.; Uchiyama, M. In situ generation of silyl anion species through $\mathrm{Si}-\mathrm{B}$ bond activation for the concerted nucleophilic aromatic substitution of fluoroarenes. ChemPlusChem 2019, 84, 277-280; (c) Gu, Y.; Shen, Y.; Zarate, C.; Martin, R. A mild and direct site-selective $s p^{2}-\mathrm{C}-\mathrm{H}$ silylation of (poly)azines. J. Am. Chem. Soc. 2019, 141, 127-132; (d) Liu, X.-W.; Zarate, C.; Martin, R. Base-mediated defluorosilylation of $\mathrm{C}\left(\mathrm{sp}^{2}\right)-\mathrm{F}$ and $\mathrm{C}\left(\mathrm{sp}^{3}\right)-\mathrm{F}$ bonds. Angew. Chem., Int. Ed. 2019, 58, 2064-2068; (e) Uematsu, R.; Yamamoto, E.; Maeda, S.; Ito, H.; Taketsugu, T. Reaction mechanism of the anomalous formal nucleophilic borylation of organic halides with silylborane: combined theoretical and experimental studies. J. Am. Chem. Soc. 2015, 137, 4090-4099; (f) Yamamoto, E.; Ukigai, S.; Ito, H. Boryl substitution of functionalized aryl-, heteroaryland alkenyl halides with silylborane and alkoxy base: expanded scope and mechanistic studies. Chem. Sci. 2015, 6, 2943-2951; (g) Yamamoto, E.; Izumi, K.; Horita, Y.; Ito, H. Anomalous reactivity of silylborane: transition-metal-free boryl substitution of aryl, alkenyl, and alkyl halides with silylborane/alkoxy base systems. J. Am. Chem. Soc. 2012, 134, 19997-20000. (h) Gao, P.; Wang, G.; Xi, L.; Wang, M.; Li, S.; Shi, Z. Transition-metal-free defluorosilylation of fluoroalkenes with silylboronates. Chin. J. Chem. 2019, 37, 1009-1014.
(10) For reviews on silyl anions, see: (a) Lerner, H.-W. Silicon derivatives of group 1, 2, 11 and 12 elements. Coord. Chem. Rev. 2005, 249, 781-798; (b) Sekiguchi, A.; Lee V. Y.; Nanjo, M. Lithiosilanes and their application to the synthesis of polysilane dendrimers. Coord. Chem. Rev. 2000, 210, 11-45; (c) Kawachi, A.; Tamao, K. Preparations and reactions of functionalized silyllithiums. Bull. Chem. Soc. Jpn. 1997, 70, 945-955.

(11) (a) George, M. V.; Peterson, D. J.; Gilman, H. Preparation of silyl- and germylmetallic compounds. J. Am. Chem. Soc. 1960, 82, 403-406; (b) Oestreich, M.; Auer, G.; Keller, M. On the mechanism of the reductive metallation of asymmetrically substituted silyl chlorides. Eur. J. Org. Chem. 2005, 184-195.

(12) For examples of the generation of functionalized silyl lithium compounds, see: (a) Tamao, K.; Kawachi, A.; Ito, Y. The first stable functional silyl anions: (aminosilyl)lithiums. J. Am. Chem. Soc. 1992, 114, 3989-3990; (b) Tamao, K.; Kawachi, A. Reduction of phenylchlorosilanes with lithium 1-(diemthylamino)naphthalenide: a new access to functionalized silyllithiums. Organometallics 1995, 14, 3108-3111; (c) Kawachi, A.; Tamao, K. Different modes of reaction of monoalkoxy- and dialkoxyphenylchlorosilanes with lithium metal: selective formation of (2-alkoxydisilanyl)lithium vs (dialkoxysilyl)lithium. Organometallics 1996, 15, 4653-4656; (d) Kawachi, A.; Tamao, K. Structures of [(amino)phenylsilyl]lithiums and related compounds in solution and in the solid state. J. Am. Chem. Soc. 2000, 122, 1919-1926; (e) Kawachi, A.; Oishi, Y.; Kataoka, T.; Tamao, K. Preparation of sulfur-substituted silyllithiums and their thermal degradation to silylenes. Organometallics 2004, 23, 2949-2955; (f) Iwamoto, T.; Okita, J.; Kabuto, C.; Kira, M. Sila-metalation route to hydrido(trialkylsilyl)silyllithiums. J. Am. Chem. Soc. 2002, 124, 11604-11605.

(13) Boebel, T. A.; Hartwig, J. F. Iridium-catalyzed preparation of silylboranes by silane borylation and their use in the catalytic borylation of arenes. Organometallics 2008, 27, 6013-6019.

(14) Boebel, T. A.; Hartwig, J. F. Silyl-directed, iridium-catalyzed ortho-borylation of arenes. a one-pot ortho-borylation of phenols, arylamines, and alkylarenes. J. Am. Chem. Soc. 2008, 130, 7534-7535.

(15) (a) Karatsu, T. Photochemistry and photophysics of organosilane and oligosilanes: updating their studies on conformation and intramolecular interactions. J. Photochem. Photobiol., C 2008, 9, 111137; (b) Tsuji, H.; Michl, J.; Tamao, K. Recent experimental and theoretical aspects of the conformational dependence of UV absorption of short chain peralkylated oligosilanes. J. Organomet. Chem. 2003, 685, 9-14.

(16) Our investigation was inspired by transition-metal-catalyzed C$\mathrm{H}$ borylation chemistry. For selected reviews, see: (a) Ishiyama, T.; Miyaura, N. Transition metal-catalyzed borylation of alkanes and arenes via C-H activation. J. Organomet. Chem. 2003, 680, 3-11; (b) Mkhalid, I. A. I.; Barnard, J. H.; Marder, T. B.; Murphy, J. M.; Hartwig, J. F. C-H Activation for the construction of $\mathrm{C}-\mathrm{B}$ bonds. Chem. Rev. 2010, 110, 890-931; (c) Hartwig, J. F. Regioselectivity of the borylation of alkanes and arenes. Chem. Soc. Rev. 2011, 40, 1992-2002; (d) Hartwig, J. F. Borylation and silylation of C-H bonds: a platform for diverse C-H bond functionalizations. Acc. Chem. Res. 2012, 45, 864 873; (e) Xu, L.; Wang, G.; Zhang, S.; Wang, H.; Wang, L.; Liu, L.; Jiao, J.; Li, P. Recent advances in catalytic C-H borylation reactions. Tetrahedron 2017, 73, 7123-7157.

(17) Our investigation was also inspired by transition-metal-catalyzed silylation reactions with hydrosilanes. For selected reviews, see: (a) Nakajima, Y.; Shimada, S. Hydrosilylation reaction of olefins: recent advances and perspectives. RSC Adv. 2015, 5, 20603-20616; (b) Zaranek, M.; Pawluc, P. Markovnikov hydrosilylation of alkenes: how an oddity becomes the goal. ACS Catal. 2018, 8, 9865-9876; (c) Xu, Z.; Huang, W.-S.; Zhang, J.; Xu, L.-W. Recent advances in transitionmetal-catalyzed silylations of arenes with hydrosilanes: $\mathrm{C}-\mathrm{X}$ bond cleavage or $\mathrm{C}-\mathrm{H}$ bond activation synchronized with $\mathrm{Si}-\mathrm{H}$ bond activation. Synthesis 2015, 47, 3645-3668.

(18) The Rh- and Pt-catalyzed borylation of hydrosilane $\mathbf{2 h}(1.0$ equiv) with $\mathrm{B}_{2}$ (pin) 3 (1.2 equiv) also provided the corresponding silylborane product $(\mathbf{1 h})$ in good yield. For the details of the optimization study, see the Supporting Information (Table S4)

(19) The original conditions reported by Hartwig use an excess of silane (4.0 equivalents) and $\mathrm{B}_{2}(\mathrm{pin})_{2}$ is the limiting reagent (cf. ref. 9). 
Here, we compared catalytic activities under conditions where the silane is the limiting reagent, while 2.5 equivalents of $\mathrm{B}_{2}(\text { pin })_{2}$ is used. This stoichiometric difference is responsible for the results that are different from the original report (cf. ref. 13).

(20) Reactions on the $5 \mathrm{mmol}$ scale using Rh- or Pt-catalysts were also investigated; for details, see the Supporting Information.

(21) (a) Keske, E. C.; Moore, B. D.; Zenkina, O. V.; Wang, R.; Schatte, G.; Crudden, C. M. Highly selective directed arylation reactions via back-to-back dehydrogenative $\mathrm{C}-\mathrm{H}$ borylation/arylation reactions. Chem. Commun. 2014, 50, 9883-9886; (b) Zhong, L.; Zong, Z.H.; Wang, X.-C. $N$-Heterocyclic carbene enabled rhodium-catalyzed ortho- $\mathrm{C}\left(s p^{2}\right)-\mathrm{H}$ borylation at room temperature. Tetrahedron 2019, 75 , 2547-2552.

(22) Meng, Y.; Kong, Z.; Morken, J. P. Catalytic Enantioselective Synthesis of anti-vicinal silylboronates by conjunctive cross-coupling. Angew. Chem. Int. Ed. 2020, 59, 8456-8459.

(23) Lee, K.-s.; Hoveyda, A. H. Enantioselective conjugate silyl additions to cyclic and acyclic unsaturated carbonyls catalyzed by $\mathrm{Cu}$ complexes of chiral $N$-heterocyclic carbenes. J. Am. Chem. Soc. 2010, 132, 2898-2900.

(24) Xue, W.; Qu, Z.-W.; Grimme, S.; Oestreich, M. Copper-catalyzed cross-coupling of silicon pronucleophiles with unactivated alkyl electrophiles coupled with radical cyclization. J. Am. Chem. Soc. 2016, $138,14222-14225$.

(25) Guo, H.; Chen, X.; Zhao, C.; He, W. Suzuki-type cross coupling between aryl halides and silylboranes for the syntheses of aryl silanes. Chem. Commun. 2015, 51, 17410-17412.

(26) (a) Tamao, K.; Ishida, N.; Tanaka, T.; Kumada, M. Silafunctional compounds in organic synthesis. Part 20. hydrogen peroxide oxidation of the silicon-carbon bond in organoalkoxysilanes. Organometallics 1983, 2, 1694-1696; (b) Weber, A.; Dehn, R.; Schläger, N.; Dieter, B.; Kirschning, A. Total synthesis of the antibiotic Elansolid B1. Org. Lett. 2014, 16, 568-571.

(27) (a) O'Brien, J. M.; Hoveyda, A. H. Metal-free catalytic C-Si bond formation in an aqueous medium. enantioselective NHCcatalyzed silyl conjugate additions to cyclic and acyclic $\alpha, \beta$-unsaturated carbonyls. J. Am. Chem. Soc. 2011, 133, 7712-7715; (b) Wu, H.; Garcia, J. M.; Haeffner, F.; Radomkit, S.; Zhugralin, A. R.; Hoveyda, A. H. Mechanism of NHC-catalyzed conjugate additions of diboron and borosilane reagents to $\alpha, \beta$-unsaturated carbonyl compounds. $J$. Am. Chem. Soc. 2015, 137, 10585-10602.

(28) Kawachi, A.; Minamimoto, T.; Tamao, K. Boron-metal exchange reaction of silylboranes with organometallic reagents: a new route to aryl silyl anions. Chem. Lett. 2001, 30, 1216-1217.

(29) Ahmed, M. A. K.; Wragg, D. S.; Nilsen, O.; Fjellvåg, H. Synthesis and properties of ethyl, propyl, and butyl hexa-alkyldisilanes and tetrakis(tri-alkylsilyl)silanes. Z. Anorg. Allg. Chem. 2014, 640, 29562961.

(30) Ito, H.; Horita, Y.; Yamamoto, E. Potassium tert-butoxide-mediated regioselective silaboration of aromatic alkenes. Chem. Commun. 2012, 48, 8006-8008.

(31) For the reaction between $\mathrm{PhMe}_{2} \mathrm{Si}-\mathrm{B}($ pin) (1a) and $\mathrm{K}(\mathrm{O}-t-\mathrm{Bu})$ in the presence of 18-crown-6, which produced $\mathrm{PhMe}_{2} \mathrm{Si}-\mathrm{K}$ (18-crown6), see: Kleeberg, C.; Borner, C. On the reactivity of Silylboranes toward Lewis bases: heterolytic B-Si cleavage vs. adduct formation. Eur. J. Inorg. Chem. 2013, 2799-2806.

(32) We conducted an in situ ${ }^{11} \mathrm{~B}\{1 \mathrm{H}\}$ NMR experiment for the reaction of Me-B(pin) with MeLi in THF- $d_{8}$ to identify the compound that resonates at $8.2 \mathrm{ppm}$ in the ${ }^{11} \mathrm{~B}\{1 \mathrm{H}\}$ NMR spectrum. The thus obtained spectrum showed that the signal derived from Me-B(pin) $(\delta 33.2$ ppm) completely disappeared, and that a new broad signal $(\delta-4.8 \mathrm{ppm})$ had emerged, indicating that the $\mathrm{Me}-\mathrm{B}(\mathrm{pin}) / \mathrm{MeLi}$ ate complex is most likely generated. The signal attributed to the $\mathrm{sp}^{3}$-hybridized boron atom of the Me-B(pin)/MeLi ate complex $(\delta-4.8 \mathrm{ppm})$ was not observed in the reaction of $\mathbf{1 f}$ with $\mathrm{MeLi}$, suggesting that the small signal $(\delta 8.2$ ppm) should most likely be attributed to the $\mathrm{sp}^{3}$-hybridized boron atom of $\mathbf{1 4}$ (for details, see the Supporting Information).

(33) The DFT-calculated ${ }^{29} \mathrm{Si}$ NMR shift for ${ }^{i} \mathrm{Pr}_{3} \mathrm{Si}-\mathrm{Li}$ is $18.7 \mathrm{ppm}$ relative to $\mathrm{Me}_{4} \mathrm{Si}$; for details, see the Supporting Information (Table S12) and: Auer, D.; Kaupp, M.; Strohmann, C. "Unexpected" ${ }^{29} \mathrm{Si}$
NMR chemical shifts in heteroatom-substituted silyllithium compounds: a quantum-chemical analysis. Organometallics 2004, 23, 3647-3655. 
Graphical Abstract

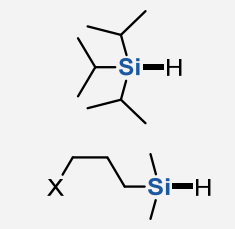

$\mathrm{X}=\mathrm{CO}_{2}(i-\mathrm{Pr}), \mathrm{Cl}, \mathrm{Ph}$ etc

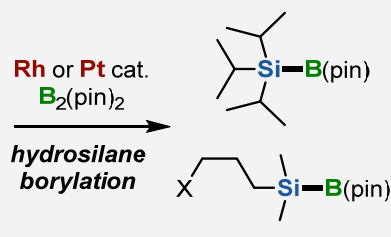

- steric hinderance - functional groups

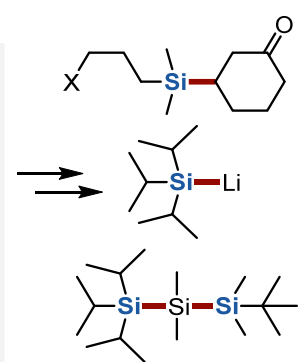

